Case report

\title{
A summary report of the workshop on the 'academic leadership training in the AIMST University, Malaysia’
}

\author{
Subhash J. Bhore* \\ Department of Biotechnology, Faculty of Applied Sciences, AIMST University, Bedong 08100, Kedah, Malaysia
}

\section{A R T I C L E I N F O}

\section{Article history:}

Received 12 March 2013

Accepted 14 April 2013

Available online 16 May 2013

\section{Keywords:}

Business model

Educational excellence

Global education

Higher education

Malaysia

\begin{abstract}
A B S T R A C T
In Malaysia, there are 81 (as on February 15, 2013) higher education institutions including satellite branches of the foreign universities. In northern part of the Peninsular Malaysia, AIMST University is the first private not-for-profit university and aims to become a premier private university in the country and the region. The workshop described in this article was designed to develop and enhance the capacity of academic staff-in-leadership-role for the University. This type of workshops may be a good method to enhance the leadership qualities of the head of each unit, department, school and faculty in each university.
\end{abstract}

Copyright (c) 2013, InPharm Association, Published by Reed Elsevier India Pvt. Ltd. All rights reserved.

\section{Workshop report}

Providing quality education is the priority of the most of the countries. In fact, the quality of the education and its real impact determines the overall progress of the countries, regions, continents and the whole world. 'Education and training' is one of the pillars of the knowledge economy. Therefore, many countries including Malaysia have opened their doors for the well-recognized foreign universities to establish their satellite campuses. This strategy in higher education provides plenty of choices to the students, and in a way it keeps all universities on their toes to maintain the quality and to attract the students. In Malaysia, there are 81 (as on February 15, 2013) higher education institutions (HEI), 26 public and 55 private; it means one HEIs for about 366,000 population, based on the current population $(29,627,713)$ of the Malaysia.

In general, universities are extremely careful in maintaining the quality of their various degree programs offered. To achieve the excellence and sustainable growth, effective and efficient leadership at all level within each university is of a prime importance. In other words, leaders (academic and non-academic) at all level within (any) university should be on the same-page in order to achieve the common goals of the departments, faculties and the university.

\footnotetext{
* Kawadgaon, Taluka: Jamkhed, District: Ahmednagar, Maharashtra 413201, India. Tel: +60 4429 8176; fax: +60 44298109 .

E-mail addresses: subhashbhore@gmail.com, subhash@aimst.edu.my.
}

On February 15 and 16, 2013, the AIMST University hosted two day workshop entitled, 'Leadership Camp: A workshop on the academic leadership training in the AIMST University' at the Rainbow Paradise Hotel, Penang Island, Malaysia. The main purpose of this workshop was to bring together various (academic and nonacademic) existing and potential leaders such as coordinators of the undergraduate and postgraduate programs, heads or functional heads of the various departments or schools or units, deans of the faculties, members of the senior management team (SMT), and other stakeholders of the AIMST University to discuss various issues important for the university, and to absolutely make sure that all leaders within university are aware of the challenges, facts, current scenario and the future direction of the organization.

In total, 54 participants from 7 Faculties and 6 Departments of the university and 2 observers from other institutions were participated in the workshop. The main speaker and facilitator of the workshop was Prof. Dr. R. Premkumar (VC, AIMST University, Malaysia). The future challenges to the university, current state of the affairs, future direction of the university and various other issues related to the university were discussed (360 degree analysis) in the workshop; however, only the essence of the workshop is reported in this article.

In the workshop-opening-talk, Premkumar highlighted that the 'strategic alignment', 'developing and monitoring of the balanced scorecard', and 'premium execution' are the three main essential components of the whole university operation (Fig. 1). As a matter of the fact, the efficiency and effectiveness of these three components determines the overall excellence of each university. 


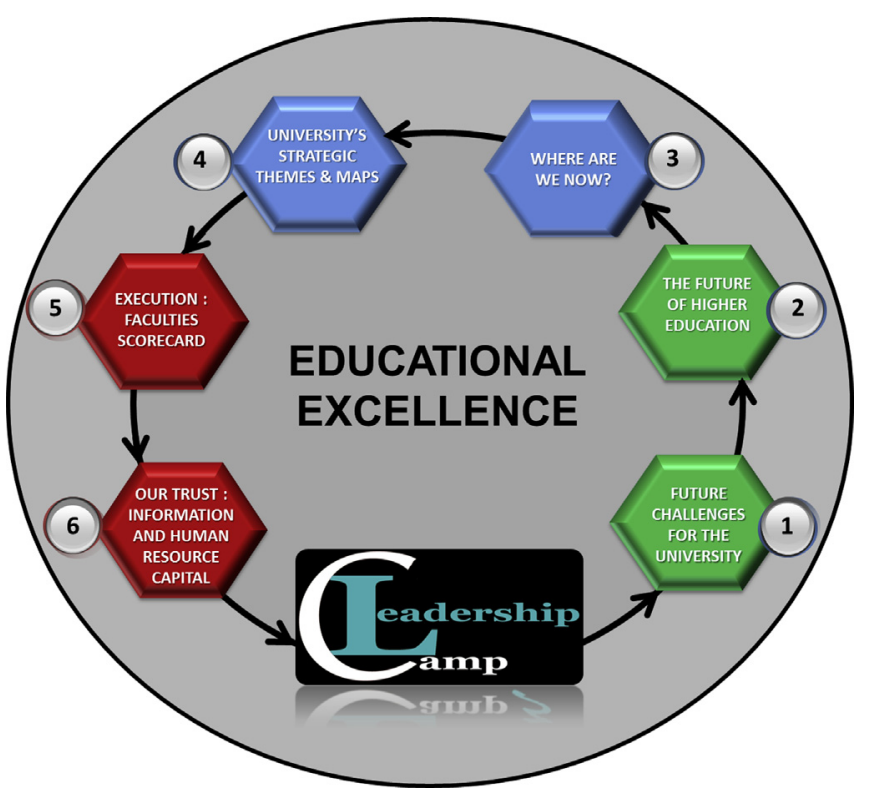

Fig. 1. Graphical view of the workshop content (Educational Excellence Business Model) showing the main six components which were discussed in the workshop, 'Leadership Camp'.(Courtesy: R. Premkumar)

While discussing future challenges for the universities in general, speaker highlighted that due to commercialization of the education and fierce competition, both old and new universities are going to have a tough time in maintaining academic excellence and delivering quality teaching and research. Attracting new talent (staff), developing commercial skills capabilities, changing management style to adopt with new business models, competing for students and government funds, keeping pace with new digital technologies, managing with regional and global mobility of the students and staff, building meaningful relationship with industry, and minimizing the dependence on the government funding are main future challenges of the universities, speaker argued. He also argued that any university should run in a business-like way for the sustainability and the overall growth. Google could be the major competitor to all existing universities; because, Google can have its own the 'Global University Online'. Google can run this type of university excellently due to its well-established global presence and network, speaker imparted with the participants. At the end of the session 1, participants were divided into small groups to discuss and debate on university's (AIMST University) survival in its current business model and the mode of operation.

Relatively similar to other countries, the ultimate aim of the Malaysia's national education philosophy is the holistic development of all the youngsters - intellectually, spiritually, emotionally, and physically. In this line, Speaker elegantly highlighted that access (to all), quality, equity, unity and efficiency are the five desired outcome that Malaysian education system aspires for. In fact, each university's duty is to make sure that graduating students are competent enough to serve in any part of the world. In this connection, speaker argued that every graduating student from the university should have six key attributes namely, knowledge, thinking skills, bi/trilingual proficiency, ethics and spirituality, and the national identity.

The education industry is rapidly evolving at national, regional and global level, hence, each university need to accommodate inevitable change. In this context, need to incorporate e-learning in university's organizational structure and need to develop e-learning professionals was quoted as examples by the Speaker.
Like public and private corporate institutions, universities can and universities should have strategic alignment in order to achieve the excellence. In this line, Premkumar highlighted that universities should align in line with the policies of the national, regional and global regulatory agencies. While speaking on strategic alignment and its importance, Dr. R. Aruljoethy (Registrar, AIMST University) highlighted that the work culture determines the productivity of the university, and work culture should be in line with the mission and vision of the university. The Human Resource Department's role in recruiting the most suitable employees is of an utmost importance in developing a dynamic and professional culture for the university, Aruljoethy argued. To make participants absolutely clear about the importance of work culture, he quoted the corporate work culture (value, practices and behavior of the staff) of Southwest Airline in line with strategy (company's goals, objectives and activities).

For any organization, institute and or company, reviewing and taking a stock of lessons learned is necessary to find out the current state of the affairs. Actually, this can help to get insights about the achievements or excellence level of the organization and the improvements made. In this line, all the participants were made aware of the achievements of the university. For the effective planning and monitoring purpose, university has categorized all the operations into four perspectives namely, 'teaching', 'financial', 'research-development-commercialization', and 'internationalization and diversity', Premkumar informed the participants while talking about where AIMST University stands. All the progress indicators (metrics) in all four perspectives will enable individual units, departments, schools, faculties and as a whole to the university to identify achievements and address the barriers, Speaker argued. In this line, the bottom-line was "you cannot manage what you do not measure".

The strategic themes serve as navigator for the university in achieving the excellence. In this link, employing the best academic staff, focusing on high quality research, and developing reputation for the delivery and professionalism should be the prime priorities of the university, Premkumar argued. He also highlighted that developing reputation for the university (which will make students proud), student's need to learn cutting age knowledge from academics, education that creates excellent career opportunities, and a stimulating environment that supports personal development are the priorities of the university. Enhancing financial resources, achieving an influential world-leading research profile, inspiring students to develop their full potential, enriching teaching and learning experience, and creating sustainable culture that supports faculty growth and development attributes should be the strategic themes of the university, speaker debated. The information capital, organizational capital and human capital of the university determines the success of the university, and serves as the strategic enablers while working on the priorities and strategic themes of the university. Therefore, in order to make participants aware of these strategic enablers - information capital, organizational capital and human capital of the university was debated openly.

The premium execution of the strategic priorities and themes is the key to success, and for the effectiveness of execution and better results, the balanced scorecards of departments, schools, units, and faculties should be in line with the university's scorecard, Premkumar claimed. For the premium execution of the university's plan (balanced scorecard), it is crucial that all heads (leaders) of the departments, schools, units, and faculties are implementing their planned initiatives/projects effectively, Speaker highlighted.

In academia, the atmosphere should be conducive, so that staff and students can perform at their best. In this line, Premkumar highlighted that it is essential for every university to create an environment that supports and promotes success, encourages staff 
and students to achieve and excel. If the students produced by university are in demand then it is a clear indication of the excellent quality and competitiveness of the students, and credit goes to the university. The universities are considered as one of the society's engines of transformation; therefore, each and every university should contribute their bit in making a change, speaker argued. He also highlighted that universities should look ahead responsibly into important new challenges to offer solutions and intellectual leadership to solve the problems of the society. Therefore, each academic staff should be a leader in his own field of expertise and students should be encouraged to think how they can shape the nation both now and in the future, speaker imparted with participants. "Achieving excellence, making a difference and leading the way" (using information and human resource capital) was quoted as university's trust by Premkumar.

In a nutshell, workshop was very unique and the insights provided by Premkumar on the 'university's business model' served as eye opener for the participants. All the sessions were very inspiring and there was an excellent interaction and deliberation. This workshop could positively enhance participant's perseverance, inquisitiveness for knowledge, and the leadership qualities. Workshop was outstandingly helpful for the participants to think out-ofbox, which could potentially help university in achieving the excellence. Nonetheless, insights from this workshop could be useful to other universities and the institutions of higher learning. Workshop was truly successful and R. Aruljoethy, N. Jivaranee, M. Sutharthan and their team of dedicated individuals deserve the appreciation for organizing this unique workshop.

\section{Sources of support}

AIMST University.

\section{Conflicts of interest}

The author has none to declare. 